\title{
Thinking Styles and Financial Characteristics of Selected Canadian Farm Managers
}

\author{
by Wayne H. Howard, ${ }^{1}$ George L. Brinkman ${ }^{1}$ and Remy Lambert ${ }^{2}$ \\ ${ }^{1}$ Department of Agricultural Economics and Business, University of Guelph, Guelph, \\ Ontario. \\ ${ }^{2}$ Departement d'Économie Rural, Université Laval, Saint-Foy (Québec).
}

\begin{abstract}
The thinking styles of selected Canadian farm managers are identified using the life styles inventory (LSI). The farmers' LSI scores are compared with those of a base sample of nonfarmers, and correlations between the farmers' LSI scores and financial indicators are examined. Results indicate that farmers do thinking differently than nonfarmers and that there are significant correlations between thinking styles and financial measures.
\end{abstract}

Nous avons examiné les modes de raisonnement de certains exploitants agricoles canadiens au moyen du Répertoire des styles de vie (LSI). Les notations LSI des chefs d'exploitation agricole étaient comparées à celles d'un échantillon repère de non-agriculteurs et nous avons étudié les corrélations entre les notations des agriculteurs et des indicateurs financiers. Il ressort de notre observation que la tournure de raisonnement des exploitants agricoles est différente de celle des non-agriculteurs et qu'il existe des corrélations significatives entre ces tournures et les mesures de performance financière.

\section{INTRODUCTION}

Do farmers think differently than other people, and do successful farmers think differently than less successful farmers? For close to a century, farm management researchers have talked of the uniqueness of the agriculture sector and have searched for the management practices and/or characteristics that differentiated the more successful farmers (Howard and Brinkman 1994). Management practices and financial characteristics are important in determining a farm's overall success, but it is the individual decision maker who guides the farm business and is responsible for whether the farm expands and succeeds. How that decision maker will react in a given situation, basically how he/she thinks, can be viewed as a psychological question in an economics context.

Instruments have been developed and calibrated to group individuals into defined psychological clusters or types. The Myers Briggs Type Indicator (MBTI) is one such instrument that has been used to distinguish a number of psychological characteristics related to business management. For example, some managers have characteristics that give them an advantage in human resources management, while other managers may have characteristics more suited to production and operations management (McKenney and Keen 1974). Using the MBTI to explore the psychology of farmers, Jose and Crumly (1993) found that a group of Nebraska farmers were significantly different from the general population, with implications for all who work with farm groups. However, the MBTI, while widely known and used, is only one of many psychological profile instruments. It may be worthwhile to see if other instruments also find that farmers are different from other people.

This note examines the thinking style of selected Canadian farm managers through the life styles inventory (LSI) (Human Synergistics 1989) and the relationships between a farmers' LSI score and financial 
characteristics of his/her farm. In effect, the objectives are to determine whether:

- farmers think differently than do nonfarmers

- there are specific thinking styles associated with financial measures.

Knowing the thinking styles of farmers may aid in targeting marketing campaigns and credit programs specifically to farmers, help with designing effective extension programs, and generally provide insights as to how farmers think for those who work directly with farmers.

\section{THEORETICAL BACKGROUND}

Two farmers facing a common set of market prices could be similar in all identifiable aspects, such as levels of technology, capital resources, and demographic variables, but have significantly different farm profits. There are number of possible explanations for the difference in profits; e.g., differences in managerial abilities (Howard, Brinkman and Lambert 1994) or risk preferences (Gunjal and Legault 1995). Another possible explanation is the farmers' self-concept and how they view the world. A farm manager with a self-concept of "farm worker" may view the world differently from a farm manager with a self-concept of "entrepreneur and agribusiness manager." In a given situation, one might see a challenge while the other sees an opportunity. Differences in self-concept and way of viewing the world are difficult to measure but may be determining factors as to why one farmer is more successful than another.

The LSI identifies thinking styles and self-concepts. Thinking styles are viewed as a combination of values, which lead to attitudes and subsequent behaviors. In turn, these behaviors have consequences for the individual's perceptions of his/her relations with the world (Human Synergistics 1989). These factors contribute to the self-concept; i.e., the intellectual, social, psychological and physical image that people have of themselves. An important assumption supporting the LSI is that thinking styles and self-con- cepts indicate how people will behave in a given situation. If this assumption is correct, then thinking styles affect the individual's ability to cope with stress, their interpersonal styles, leadership effectiveness, and overall job performance. Hence, a farm manager's thinking style and self-concept directly relate to that farmer's ability to deal with and to solve problems, initiate change and perform effectively.

The LSI measures 12 different thinking patterns based on the response to 240 words or phrases. A sample of the LSI instrument is in Table 1. A respondent is asked to consider each word or phrase and circle 2, 1 or 0 if word or phrase ". . . is like you most of the time, ... some of the time, ... [or] essentially unlike you" (Human Synergistics 1989). The $(2,1,0)$ responses are tabulated into indices for each of the 12 thinking styles. The reliabilities of the indices range from 0.80 to 0.88 and average 0.84 (Cooke and Rousseau 1983a). Together, the 12 styles identified by the LSI indices explain approximately $70 \%$ of the variance in thinking/behavior style measures (Cooke and Rousseau 1983b; Ware, Leak and Perry 1985).

The 12 thinking patterns identified by the LSI are listed in Table 2, along with the characteristics used to define the patterns. The 12 patterns are based in part on Maslow's hierarchial lower-order and higher-order human needs, only expanded into 12 patterns rather than the five needs identified by Maslow (1954). Moreover, the styles are not hierarchial; the 12 LSI styles are seen as a continuum of needs and orientation. In addition to Maslow's basic needs, other styles are identified based on the works of other theorists (McClelland et al 1953), management theorists (McGregor 1960), and personality psychologists (Rodgers 1961; Horney 1945; Sullivan 1953).

Responses to the LSI are usually scored on the circumplex pictured in Figure 1. The concentric rings from the centre of the circumplex indicate the 10th, 25th, 50th, 75th and 90th percentiles of responses. For example, the circumplex for a manager who ranked in the 90th percentile on ACHIEVE- 
Table 1. Sample words and phrases from the life styles inventory

\begin{tabular}{|c|c|c|}
\hline & $\begin{array}{r}\text { Responses } \\
0=\text { essentially unli } \\
1=\text { like you some o } \\
2=\text { like you most of }\end{array}$ & \\
\hline Wor & & \\
\hline 1 & humanistic & $\begin{array}{lll}0 & 1 & 2\end{array}$ \\
\hline 2 & thoughtful & $\begin{array}{lll}0 & 1 & 2\end{array}$ \\
\hline$\ldots$ & & \\
\hline 238 & not easily upset & $\begin{array}{lll}0 & 1 & 2\end{array}$ \\
\hline 239 & high personal integrity & $\begin{array}{lll}0 & 1 & 2\end{array}$ \\
\hline 240 & exciting to know & $\begin{array}{lll}0 & 1 & 2\end{array}$ \\
\hline
\end{tabular}

Source: Human Synergistics (1989).

MENT (11 o'clock position), will have the 11 o'clock position shaded out to the second to the last ring. The dark ring, third from the centre, is the 50th percentile, or average response. A score for a style that is shaded beyond the third, dark ring represents a stronger tendency by the respondent (or group of respondents) toward this style than is found in the base population. It is important to note that there are no right or wrong scores in the LSI, only scores that are closer to or more divergent from the base population mean.

The thinking styles have been classified in two ways to facilitate interpretation of the results (Human Synergistics 1989). These classifications are shown schematically in the two outermost rings on the Circumplex in Figure 1. First, following Maslow, there are lower-order "security needs" (thinking styles OPPOSITIONAL, AVOIDANCE and DEPENDENT), and higher-order "satisfaction needs" (ACHIEVEMENT, SELFACTUALIZING and HUMANISTICENCOURAGING). The remaining six thinking styles indicate if one is more oriented toward "tasks" (POWER, COMPETITIVE and PERFECTIONISTIC) or toward "people" (AFFILIATIVE, APPROVAL and CONVENTIONAL). For example, an LSI score may indicate that a manager is more "task" oriented than "people" oriented; e.g., thinking style scores associated with "tasks" are higher and hence dominate style scores associated with "people." That manager will likely do better with clearly defined physical activities than with more ambiguous leadership or "coaching" activities. A manager's orientation is relative to his/her other LSI scores and not relative to the sample mean. A manager may have very high scores in "people" styles relative to the sample mean, but still be more "task" oriented than "people" oriented if his/her "task" scores are higher than his/her "people" scores.

The second way the 12 thinking styles have been classified is into "Constructive," "Passive/Defensive" and "Aggressive/ Defensive" styles. Constructive styles (ACHIEVEMENT, SELF-ACTUALIZING, HUMANISTIC-ENCOURAGING and AFFILIATIVE) are characterized by selfenhancing thinking and behavior. The prime motivation is "satisfaction," which is realized through healthy personal relationships and working effectively with people. Passive/Defensive styles (AVOIDANCE, DEPENDENT, CONVENTIONAL and APPROVAL) represent self-protective thinking, which are motivated by "security needs." These needs are met through interaction with people. Lastly, Aggressive/ Defensive styles (OPPOSITIONAL, POWER, COMPETITIVE and PERFECTIONISTIC) represent self-promoting thinking and behavior motivated by the need to 
Table 2. Description of the LSI styles

Position Style and characteristics

1 HUMANISTIC-ENCOURAGING

Concern for the growth and development of people; willingness to assist others with self-improvement; and ability to inspire and motivate others.

2 AFFILIATIVE

Tendency to value relationships above all else; strong, well-developed interpersonal skills; and tendency to motivate others using genuine praise and friendliness.

3 APPROVAL

Low self-esteem; preoccupied with opinions of others; too agreeable and compliant; difficulties with conflict, negotiation, and confrontation.

4 CONVENTIONAL

Views rules as a source of comfort and security; covers up mistakes; reduced initiative;

\section{DEPENDENT}

feelings of security with a bureaucracy.

6 AVOIDANCE

Overly concerned with pleasing people and not questioning others or taking independent action; passive attitude; lack of self-respect; difficulty making decisions.

Tendency to deny responsibility for own behavior; feelings of guilt over real or imagOPPOSITIONAL ined mistakes; fear of failure; preoccupation with one's own concerns.

Ability to ask tough, probing questions; tendency to seem aloof and detached; need to POWER

look for flaws in everything; negative, cynical attitude; sarcastic sense of humour.

High need for power, status, prestige, influence, and control; tendency to dictate, rather than guide others; aggressive and possibly vengeful attitude; narrow, ridge thinking; tendency to be threatened by perceived attempts to undermine authority.

\section{COMPETITIVE}

Associates self-worth with winning and losing; need for recognition and praise from others; tendency toward aggressiveness; takes risk and "shoots from the hip"; extreme fear of failure.

PERFECTIONISTIC

Tendency to attach self-worth to accomplishment of tasks; repetitive, sometimes ritualistic behavior; low self-esteem; places excessive demands on self and others; preoccupation with detail that distorts perspective and judgment; excessive concern with avoiding mistakes; inability to deal with or express emotion.

Focus on achieving a standard of excellence; lack of belief in fate, luck, or chance; knowledge that individual effort counts; committed to making things better; preference for setting and accomplishing realistic, attainable goals, rather than goals imposed by

Concern for self development; strong instincts and intuition; relatively free from feelings of guilt or worry; an energetic, exciting approach to life; strong desire to know about and experience things directly.

Source: Human Synergistics (1989). 


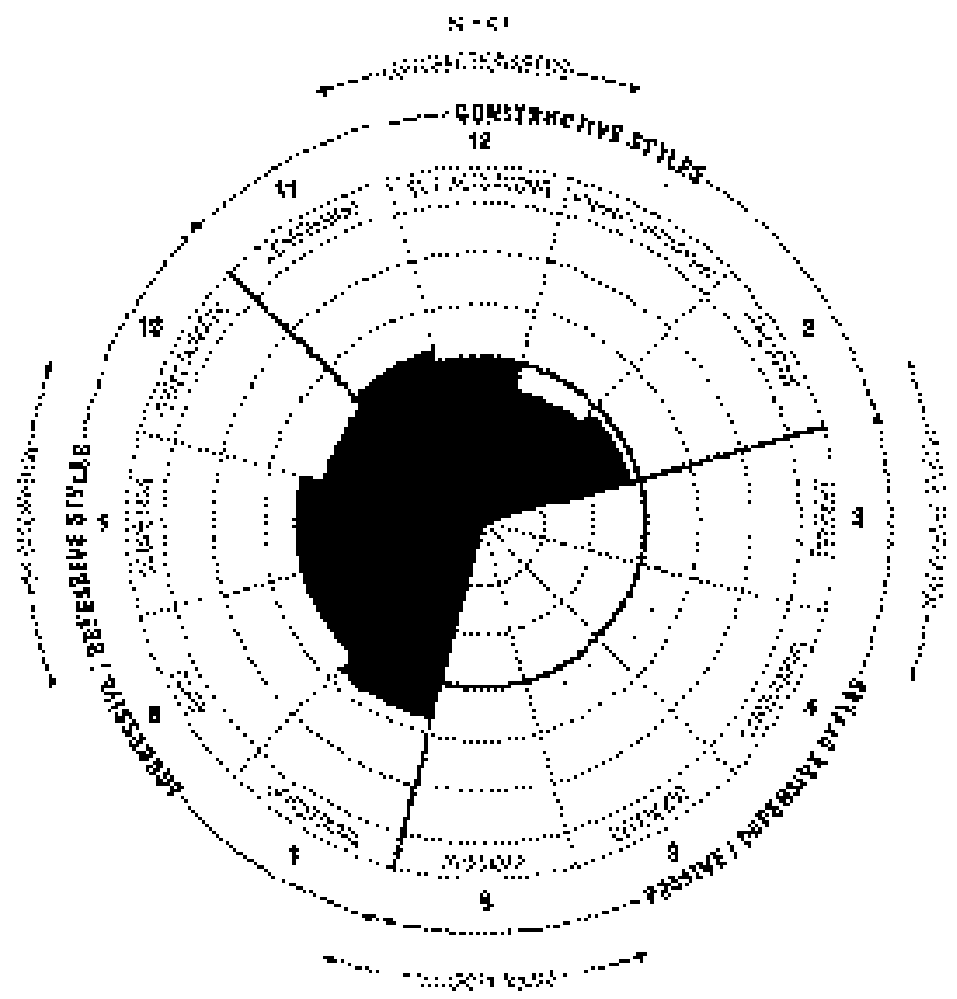

Figure 1. Circumplex of the life styles inventory Source: Human Synergistics (1989).

maintain status/power and satisfy security needs through tasks and actions. Similarly to the orientation discussed above, a manager who exhibits more of a "Constructive" style than an "Aggressive/Defensive" or "Passive/ Defensive" has higher LSI scores associated with "Constructive" styles relative to his/her scores associated with "Aggressive/ Defensive" or "Passive/ Defensive" styles. Again, this classification is relative to the individual's other LSI scores and not relative to the sample means.

The LSI was designed to enhance the effectiveness of managers within an organization by helping them to recognize and utilize their strengths and weaknesses (Cooke and Lafferty 1981). Hundreds of companies have used the LSI to enhance managerial effectiveness and to improve an organization's internal communications. The LSI was not designed to test differences among farmers and nonfarmers. However, the LSI identifies and clusters thinking styles into quantifiable measures and has a large sample of nonfarm managers and other professionals against which farmer responses can be compared. Hence, it appears to be suitable for determining whether farmers think differently than nonfarmers do, and whether there are specific thinking styles associated with farm financial success.

\section{METHODS}

\section{Instrumentation}

The LSI has been administered to over 150,000 individuals, and several tests have established the reliability and validity of the LSI for measuring thinking styles and selfconcept (Cooke and Lafferty 1981; Cooke and Rousseau 1983a and 1983b; Ware, Leak 
Table 3. Study participants by region and enterprise type

\begin{tabular}{lccccc}
\hline & \multicolumn{5}{c}{ Region } \\
\cline { 2 - 6 } Enterprise type & British Columbia & Prairie & Ontario & Quebec & Atlantic Canada \\
\hline Cash Crop & 7 & 2 & 4 & \\
Cash Crop + Livestock & 5 & 3 & & \\
Livestock (Beef/Hogs) & & 3 & 7 & 2 & 2 \\
Dairy/Poultry & 1 & 7 & 5 & 2 \\
Dairy/Mixt & 2 & & 2 & 4 & 1 \\
Fruit/Veg. & 3 & & 3 & & 5 \\
Specialty & 6 & 15 & 24 & 15 & \\
Total & & & & & \\
\hline
\end{tabular}

and Perry 1985). The sample "norm" against which the sample in this study was compared included 7376 professionals, of which 3476 were managers, 2102 teachers, and 1798 others. Summary statistics of economic and demographic characteristics of the norm are not available for comparison. It is assumed that the sample norm is comparable with the farm manager sample in terms of responsibility, education and experience, and socioeconomic status. ${ }^{1}$

\section{Study Subjects}

Sixty-five managers from across Canada were interviewed in fall 1993, with 61 of those managers completing the LSI. Study participants by region and enterprise type are reported in Table 3 . The sample represents the major commodity groups across Canada's five major geographical regions. Economic and demographic information was also collected; these characteristics are reported in Table 4. Confidentiality prevents knowing which farm managers did not complete the LSI.

Assets, gross farm sales and net farm income are considerably higher in this sample than the Canadian average. The farm managers in this study were selected from average or better commercial operators. Approximately two-thirds were classified as "top" or "good" managers, and one-third as "average" managers (Howard, Brinkman and Lambert 1994). Hence, they are not neces- sarily statistically representative of farm managers across Canada. Moreover, no limited-resource or small-scale operators are included in the sample. However, the economic variables have a wide range, which facilitates determining significant relationships between the LSI and financial variables.

\section{Statistical Design}

Pearson $t$-tests are used to determine whether the farm managers' mean LSI score was significantly different from the base population's mean score. An F-distribution is used to estimate if the variances of the scores were different. Correlations are computed for each of the 12 LSI scores and income, assets, debt/equity ratios (Snedecor and Cochran 1978).

\section{RESULTS}

The mean LSI scores by thinking style for the farm managers' sample and the base population are reported in Table 5, with the circumplex for the scores presented in Figure 1. Four patterns emerge from these results.

First, the farm managers had LSI scores significantly different from the sample norm for eight of the 12 thinking styles, as reported in Table 5. The only thinking styles not significantly different from the norm were HUMANISTIC-ENCOURAGING, DEPENDENT, POWER and PERFECTIONISTIC. 
Table 4. Personal and financial characteristics of study participants ${ }^{\mathrm{a}}$

\begin{tabular}{|c|c|c|c|}
\hline \multirow[b]{2}{*}{ Characteristic } & \multirow[b]{2}{*}{ Average } & \multicolumn{2}{|c|}{ Range } \\
\hline & & High & Low \\
\hline Age & $\begin{array}{c}46 \\
(7.3)\end{array}$ & 67 & 30 \\
\hline Years farming & $\begin{array}{c}16 \\
(9.3)\end{array}$ & 43 & 4 \\
\hline Asset value & $\begin{array}{l}\$ 2,387,000 \\
(4,811,000)\end{array}$ & $\$ 25,000,000$ & $\$ 180,000$ \\
\hline$\%$ debt & $\begin{array}{c}25 \\
(18.8)\end{array}$ & 67 & 0 \\
\hline Gross farm sales & $\begin{array}{l}\$ 1,428,000 \\
(4,377,000)\end{array}$ & $\$ 30,000,000$ & $\$ 90,000$ \\
\hline Farm income & $\begin{array}{l}\$ 215,000 \\
(515,000)\end{array}$ & $\$ 3,000,000$ & $\$ 200,000$ \\
\hline
\end{tabular}

${ }^{a}$ Standard deviations are in parentheses.

These differences in scores can be seen on the circumplex in Figure 1. For example, the farmers' mean OPPOSITIONAL score was at the 75 th percentile; i.e., on average, $75 \%$ of the sample norm had a lower OPPOSITIONAL score than did the farmers' mean score in this study. The scores on the circumplex should be interpreted carefully. The HUMANISTIC-ENCOURAGING score is below the 50th percentile on the circumplex, but not significantly so, as reported in Table 5 .

Second, the variances of the farm mangers' LSI scores were smaller than the variances from the base sample variances. These variances were significantly smaller for eight of the 12 styles, but not the same eight styles that have significantly different means. Both HUMANISTIC-ENCOURAGING and DEPENDENT were not significantly different in either means or variances, while OPPOSITIONAL and COMPETITIVE had different means, but not different variances. Both POWER and PERFECTIONISTIC had significantly smaller variances than the variances of the sample norm, but not significantly different means. It is somewhat surprising to have a smaller variance in the farmer sample that is less than $1 \%$ of the size of the sample norm.
Third, following the Maslow oriented method of classifying the responses according to "security needs" versus "satisfaction needs," and "task orientation" versus "people orientation," as shown in the circumplex in Figure 1, the farm managers' displayed generally higher scores in "security needs," "task orientation" and "people orientation" styles than in "satisfaction needs." The average farm manager's score was above the 50th percentile in seven of the nine thinking styles classified as "task orientation," "security needs" and "people orientation" styles (positions 2 o'clock to 10 o'clock on the circumplex). Only in PERFECTIONISTIC were they close to the sample norm.

Fourth, following the second classification method reported earlier, which identifies "Constructive," "Passive/Defensive" and "Passive/Aggressive" styles, the average farm manager's score was lowest on "Constructive" styles, as depicted on the circumplex in Figure 1. Within the "Constructive" styles, only the HUMANISTIC-ENCOURAGING style was below the sample norm, while ACHIEVEMENT was above the norm. However, seven of the eight styles that comprise the "Aggressive/ Defensive" and "Passive/Defensive" styles 
Table 5. LSI scores for sample and base populations ${ }^{\mathrm{a}}$

\begin{tabular}{lccc}
\hline Position & Thinking style & Sample & Norm \\
\hline 1 & HUMANISTIC & 28.88 & 29.59 \\
& & $(5.17)$ & $(5.84)$ \\
2 & AFFILIATIVE & $30.00^{*}$ & 28.02 \\
& & $(6.75) \#$ & $(8.77)$ \\
3 & APPROVAL & $14.91^{*}$ & 13.63 \\
& & $(4.69) \#$ & $(6.86)$ \\
4 & CONVENTIONAL & $16.00^{* *}$ & 14.51 \\
& & $(3.91) \#$ & $(5.51)$ \\
5 & DEPENDENT & 16.00 & 15.29 \\
& & $(4.92)$ & $(5.65)$ \\
6 & AVOIDANCE & $8.50^{* *}$ & 6.86 \\
& & $(4.30) \#$ & $(6.24)$ \\
7 & OPPOSITIONAL & $10.66^{* * *}$ & 7.90 \\
& & $(5.02)$ & $(5.49)$ \\
8 & POWER & 8.86 & 8.23 \\
& & $(5.35) \#$ & $(7.64)$ \\
9 & COMPETITIVE & $14.84^{* *}$ & 13.13 \\
& & $(5.46)$ & $(6.13)$ \\
10 & PERFECTIONISTIC & 20.09 & 20.30 \\
& & $(4.67) \#$ & $(5.96)$ \\
11 & ACHIEVEMENT & $32.52^{* * *}$ & 28.92 \\
& & $(5.24) \#$ & $(8.91)$ \\
12 & SELF-ACTUALIZING & $28.50^{* *}$ & 26.52 \\
& & $(5.73) \#$ & $(8.70)$ \\
\hline
\end{tabular}

${ }^{\text {a }}$ Standard deviations are in parentheses.

* Means statistically different at the 0.10 level.

** Means statistically different at the 0.05 level.

*** Means statistically different at the 0.01 level.

\# Variances statistically different at the 0.01 level.

had scores above the norm. Hence, the thinking styles classified as "Aggressive/ Defensive" and "Passive/Defensive" tend to dominate the "Constructive" styles for farm managers in this sample.

Each thinking style was correlated with income, assets and debt/equity ratio for each farm. Three pairs were correlated at the alpha $=0.05$ level. Both income and assets were negatively correlated with DEPENDENCE ( $p=-0.32$ for each), and debt/equity was positively correlated with OPPOSITIONAL $(p=0.23)$. Implications of these results are discussed below.

\section{DISCUSSION AND IMPLICATIONS}

There are several implications from the above results. First is that the farm managers in this sample think differently than the managers and other professionals in the sample norm. Eight of the mean LSI scores are significantly different, as are eight of the variances. The smaller variances for the farm managers may indicate only that they are a cohesive group with many common traits and characteristics due to their common occupations, but given the LSI scores, it is not heroic to extrapolate that farmers have different thinking styles and motivations 
from nonfarmers. A caveat is in order, in that these results are based on a small sample, and that the sample norm, while large and validated, does not necessarily represent the entire nonfarm population. Nevertheless, these results are consistent with those of Jose and Crumly (1993) (and "common wisdom") that farmers are different from nonfarmers.

Second, the farmers in this study are more motivated by security and status/power than by satisfaction in what they do. In terms of Maslow's hierarchial ranking of needs, they are more concerned with their lowerorder needs than with their higher-order needs, possibly because they have not satisfied their lower-order needs. This result and interpretation are counter to the "common wisdom" that farmers accept low returns from agriculture because of the "psychic income" they receive and the great satisfaction they receive from farming. ${ }^{2}$ However, this result and interpretation is in no way pejorative. The high need for security can also be interpreted as a fear of failure, which can lead to thorough planning, preparation and follow-up on projects and operations.

Third, the low scores on "constructive styles" have implications for expanding farm operations. The farmers in this sample were more task oriented than people oriented, but large and expanding operations require skills necessary to effectively manage people. The farmers in this sample appear to have an innate ability to ask tough, probing questions required for enterprise analysis, but the lack of a people orientation indicates that human resources management skills and practices must be learned to overcome a natural lack of those skills.

Fourth, if thinking styles and motivation have a direct correspondence to behavior, in particular behavior that leads to financial success or lack thereof, then instruments such as the LSI may add to the accuracy of credit scoring rules. Thinking style and motivation may be a better indicator of credit worthiness than more traditional scoring rules based on financial indicators and management ability, as proxied by age, experience and education (Turvey 1991).
Fifth, the high "Aggressive/Defensive" and "Passive/Defensive" scores relative to the low "Constructive" styles indicates a defensive approach to life, either by aggressively promoting one's self-interests through the accomplishment of tasks, or by protecting one's interests by promoting security measures. Either way, there is resistance to change. Sales people, extension agents and other promoting new products, practices or ideas should be prepared for resistance and have answers for a range of detailed, negative questions. However, the relatively high (to the sample norm) APPROVAL and CONVENTIONAL scores indicate that the farmers value their peers' opinions and willingly obey authority and social norms. Hence, farmer trials and other marketing plans that rely on farm leaders and peer endorsement may be effective and are consistent with these results.

Given these results, it may be fair to characterize the farmers in the sample as highly competitive, with that competition tempered by a need for security and fear of failure. This need for security and fear of failure, rather than hindering their risk taking as entrepreneurs, leads to good, thorough planning. Given their high OPPOSITIONAL thinking style, these farmers also have the ability to ask tough, probing questions that complement their planning. Moreover, they are quite independent. The negative correlations between DEPENDENCE and income and assets indicate that the greater their wealth and/or income, the less they are concerned with pleasing others and vice versa. The positive correlation between OPPOSITIONAL ("ask tough, probing questions; look for flaws in everything") and debt/equity can be interpreted in two plausible but opposite ways:

- being highly leveraged causes farmers to "ask tough, probing questions" because they cannot afford to make a mistake or

- being able to ask tough, probing questions contributes to the farmer's ability to manage higher levels of debt.

If thinking styles influence behavior, then the 
second explanation is more likely than the first.

The results from this study are consistent with those of Jose and Crumly (1993). Psychologists would likely pointed out many differences in purpose, design and implementation between the MBTI used by Jose and Crumly and the LSI used in this study, but the results from the two studies are very similar. First, both studies reported that the farmers sampled are significantly different from the general population. Second, both studies reported that farmers are better at managing production and operations than managing people. Third, Jose and Crumly reported that, compared with the general population, the Nebraska sample was more introverted, more sensing than intuitive and used judgment more than perception. People displaying those characteristics are most comfortable in a structured, traditional society, do not like change in their environment, and like to have time to study facts and solicit opinions from their peers about new technologies and regulations. That interpretation is consistent with the high LSI scores in CONVENTIONAL, APPROVAL and OPPOSITIONAL thinking style, which indicate comfort with rules and an ordered bureaucracy, a preoccupation with opinions of others, and the "ability to ask tough, probing questions" is consistent with wanting time "to study facts." Lastly, Jose and Crumly reported that the low number of "intuitive" thinkers in their group indicates a lack of visionary leaders. While the LSI does not directly examine "visionary" leadership potential, the "Constructive" thinking styles usually associated with leadership ability had low scores relative to the "Aggressive/Defensive" and "Passive/ Defensive" thinking styles, which are associated with opposition to new ideas and change.

The high OPPOSITIONAL score and low "Constructive" scores have implications for farm leaders and politicians. The farmers in this sample would likely meet any new ideas on farm programs and policies with a negative reaction and a cynical attitude.
However, this initial negative reaction may not reflect the farmers' ultimate opinion and acceptance of the program or policy. They might want and support the program or policy once they have fully examined it, but their initial reaction is more likely to be negative than positive. In effect, farm leaders and politicians should expect an initial no, should go slow, and should not be discouraged by the initial negative reaction to new ideas and proposals.

\section{SUMMARY}

The LSI is used to identify thinking styles of 61 farm managers from across Canada and is compared with a base sample of nonfarm managers and other professionals in order to determine whether farmers think differently than nonfarmers, and whether there is a relationship between thinking style and farm financial success. Results indicate that farmers do think differently than nonfarmers. In particular, farmers are more task and security oriented than satisfaction and people oriented, and also high in "Aggressive/ Defensive" and "Passive/ Defensive" styles and low in "Constructive" styles. Lastly, there is a significant negative correlation between income and a DEPENDENT style and assets and a DEPENDENT style. There is a positive correlation between a high debt/equity ratio and an OPPOSITIONAL style. These results may aid in targeting marketing campaigns and credit programs specifically to farmers, help with designing effective extension programs, and generally provide insights into how farmers think for those who work directly with farmers.

\section{NOTES}

1 This assumption may not be accurate, however. The farm managers' LSI scores are viewed as a measure of their thinking styles within their group, and the sample norm is treated as the population norm by LSI developers.

2 It is possible that "psychic income" is more prevalent among limited-resource or small-scale farmers, who were not part of the study sample. 


\section{ACKNOWLEDGMENT}

This research was funded in part by the Canadian Farm Business Management Council and the Ontario Ministry of Agriculture, Food, and Rural Affairs. All errors and opinions are solely the responsibility of the authors.

\section{REFERENCES}

Cooke, Robert A. and J. Clayton Lafferty. 1981. Level I: Life styles inventory — an instrument for assessing and changing the self-concept of organizational members. Ingersol, Ontario: Human Synergistics.

Cooke, R. A. and D. M. Rousseau. 1983a. Relationship of life events and personal orientations to symptoms of strain. Journal of Applied Psychology 68: 446-58.

Cooke, R. A. and D. M. Rousseau. 1983b. The factor structure of level I: Life styles inventory. Education and Psychological Measurement 43: 449-57.

Grisley, W. and E. D. Kellogg. 1983. Farmers' subjective probabilities in northern Thailand: An elicitation analysis. American Journal of Agricultural Economics 65: 74-82.

Gunjal, K. and B. Legault. 1995. Risk preferences of dairy and hog producers in Quebec. Canadian Journal of Agricultural Economics 43: 23-35.

Horney, K. 1945. Our Inner Conflicts. New York: Norton.

Howard, Wayne H. and George L. Brinkman. 1994. Farm management: Issues and trends. Canadian Farm Business Management Council, Ottawa.

Howard, Wayne H., George L. Brinkman and Remy Lambert. 1994. Identifying management differences between Canadian farm managers. Canadian Farm Business Management Council, Ottawa.

Human Synergistics. 1989. LSI 1: Self Development Guide. Ingersol, Ontario: Human Synergistics.

Jose, H. Douglas and James A. Crumly. 1993. Psychological type of farm/ranch operators: Relationship to financial measures. Review of Agricultural Economics 15 (1): 121-32.

Maslow, A. H. 1954. Motivation and Personality. New York: Harper and Row.

McClelland, D. C., J. W. Atkinson, R. A. Clark, and E. L. Lowell. 1953. The Achievement Motive. New York: Appleton-Century-Crofts.

McGregor, D. 1960. The Human Side of Enterprise. New York: McGraw-Hill.

McKenney, J. L. and P. G. Keen. 1974. How managers' minds work. Harvard Business Review 52: 79-90.

Rodgers, C. R. 1961. On Becoming a Person: A Therapist's View of Psychotherapy. Boston: Houghton-Mifflin.

Snedecor, George W. and William G. Cochran. 1978. Statistical Methods. 6th ed. Ames, Iowa: Iowa State University Press.

SriRamaratnam, S., D. A. Bessler, M. E. Rister, J. E. Matocha and J. Novak. 1987. Fertilization under uncertainty: An analysis based on producer yield expectations. American Journal of Agricultural Economics 69: 349-57.

Sullivan, H. S. 1953. The Interpersonal Theory of Psychiatry. New York: Norton.

Turvey, Calum Greig. 1991. Credit scoring for agricultural loans: A review with applications. Agricultural Finance Review 51 (1): 43-54.

Ware, M. E., G. K. Leak and N. W. Perry. 1985. Life styles inventory: Evidence for its factor validity. Psychological Reports 56: 963-68. 